\title{
An Adaptive Network Model for Burnout and Dreaming
}

\author{
Mathijs Maijer ${ }^{1}$, Esra Solak $^{1}$, and Jan $\operatorname{Treur}^{2(凶)}$ \\ 1 Computational Science, University of Amsterdam, Amsterdam, The Netherlands \\ m.f.maijer@gmail.com, s.3.solak@gmail.com \\ 2 Social AI Group, Vrije Universiteit Amsterdam, Amsterdam, The Netherlands \\ j.treur@vu.nl
}

\begin{abstract}
As burnouts grow increasingly common, the necessity for a model describing burnout dynamics becomes increasingly apparent. The model discussed in this paper builds on previous research by adding dreams, a component that has been shown to have an adaptive regulating effect on emotions. The proposed model is a first-order adaptive temporal-causal network model, incorporating emotions, exercise, sleep, and dreams. The model was validated against given patterns found in empirical literature and it may be used to gain a better understanding of burnout dynamics.
\end{abstract}

\section{Introduction}

A burnout is seen as a buildup of long-term unresolved work-related stress. Recently, the World Health Organization (WHO) has classified an occupational burnout as a syndrome [1]. There may be multiple causes for the development of this syndrome, but according to the WHO, it can arise from a failure to manage chronic work-related stress. This can cause feelings of energy depletion, exhaustion, job detachment, negative feelings and cynicism towards the job, and reduced professional efficacy as put forward in [1]. The number of people complaining about burnout related symptoms has increased over time and it is rising fast. In 2015, $13 \%$ of the Dutch employees mentioned burnout symptoms, this figure has risen to $16 \%$ by 2017 as shown in [2, 3]. Around $20 \%$ of employees aged between 25 and 35 have mentioned burnout symptoms in the Netherlands.

Due to the increase in burnout complaints and the severity of the issue, it has become more important to not only analyse the causes of burnouts, but also how to prevent, avoid, and if possible, cure them. A few possibilities to fight against burnouts may be lifestyle or habit changes. This paper uses previous research on modeling burnout phenomena [4, 5], to build forth on the already created temporal-causal network models that describe the burnout syndrome as a dynamic interplay between symptoms in line with [6]. In [4], the initial model was created and the effects of physical exercise were analysed, in [5] sleep factors were added to improve the model. This paper adds relevant dream components as described in [7] and also makes the model adaptive, resulting in a firstorder adaptive temporal-causal network model. The main adaptive network-oriented modelling approach was adopted from [8]. 
The aim is to gain a better understanding of the development of burnouts and to create a more realistic model that can be used in real-life scenarios. In Sect. 2, a brief overview of the relevant background knowledge will be provided; in Sect. 3, the network-oriented modelling approach will be explained in some detail. In Sect. 4, the designed adaptive network model will be described. Multiple simulations will be given in Sect. 5. Section 6 and Sect. 7 will respectively address empirical and mathematical validation of the model. Finally, a discussion concludes the paper.

\section{Theoretical Background}

This paper assumes the classic definition of the burnout by Maslach and Jackson [9]. It describes the symptoms of emotional exhaustion, a decline in experiencing personal accomplishment, and a sense of depersonalization. These symptoms are also described in the WHO classification of a burnout provided in [1]. The main idea behind the definition of Maslach and Jackson, was to invent a measurement instrument for burnouts [9]. Various components are mentioned that interact together to form a burnout. The most important components are described as risk factors and suppressive factors, also called protective factors. Among the risk factors are subjective stress, job ambiguity, work pressure, thoughts of work during leisure time, the amount of sleep, and the quality of sleep. Protective factors are, for example, confidence, or the amount of physical exercise, as modeled in [4] and sleep modeled in [5]. Factors that influence the progression or development of burnout symptoms are influenced by personal characteristics as described in [10]. For example, neuroticism has shown a strong correlation with experiencing stress. Next to this, openness has been shown to be negatively correlated with depersonalization and emotional exhaustion as discussed in [11]. Because of the link between openness and physical exercise addressed, for example, in [12], previous recomputational modeling search has analyzed the effects of physical exercise on the dynamics of a burnout [4]. In [5], the relation between sleep and burnout dynamics is analysed. This is partially done by analysing the results of a questionnaire which showed that insufficient sleep can be used as a predictive factor for clinical burnout as put forward in [13]. A noteworthy finding is that the amount of sleep is a better predictor for a clinical burnout than the amount of stress someone experiences at work.

Next to sleep, dreams have been found to have a regulating effect on some emotions as described by [7, 15-17] which is considered a form of internal simulation. The internal simulation consists of activation of memory elements, which are sensory representations in relation to emotions. Dream episodes occur after competing, which will activate different sensory representations (e.g., images) during dreams. The level of how much the feeling states and sensory representations are activated is controlled by different control states. In [7], Ch 5, an adaptive temporal-causal network model is introduced to model dream dynamics that shows a form of adaptiveness called fear extinction as described in [17]. Here emotion regulation is included of which the connections become stronger as they are used more according to the principle of Hebbian learning as discussed in [18]. Figure 1 shows a conceptual representation of part of the adaptive temporal-causal network model that is presented in [7], Ch. 5, Fig. 5.1. Five states are shown, a sensory representation state, an emotion regulation control state, a dream episode state, a feeling 
state and a preparation for a bodily response state. The red arrows indicate inhibition, or a negative impact, and the black and green arrows indicate a positive impact, where the green arrows are adaptive.

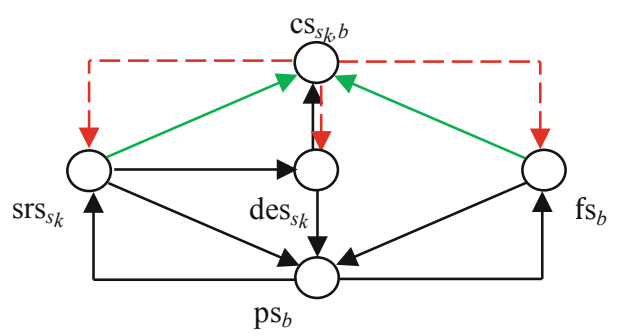

Fig. 1. Conceptual representation of part of an adaptive temporal-causal network model for dream dynamics. Here, (1) the arrows between $\mathrm{srs}_{s_{k}}$ and $\mathrm{ps}_{b}$ indicate the bidirectional associations between sensory representations $\mathrm{srs}_{s_{k}}$ and emotional fear responses $\mathrm{ps}_{b}$, (2) the arrows between $\mathrm{ps}_{b}$ and $\mathrm{fs}_{b}$ indicate an as-if body loop generating fear feelings $\mathrm{fs}_{b}$, (3) the arrow from sensory representation srs $_{s_{k}}$ to dream episode des $_{s_{k}}$ indicates the triggering of a (pseudo-conscious) dream episode, (4) the arrow from $\operatorname{des}_{s_{k}}$ to $\mathrm{ps}_{b}$ indicates the (amplifying) impact of the dream episode on the emotional fear response, (5) the upward arrows from $\operatorname{des}_{s_{k}}$ to emotion regulation control state $\mathrm{cs}_{s_{k}, b}$ indicate monitoring of the (emotional) state of the person, and (6) the red dotted downward arrows indicate suppression of the target states as a form of emotion regulation. (Color figure online)

\section{Network-Oriented Modelling}

The temporal-causal network model presented here was designed using a networkoriented modelling approach that is described in [7] and [8]. Network-Oriented Modelling uses nodes and edges, which are the connections between nodes. Nodes are states with values that vary over time, while the connections can be seen as the causal relationships between these nodes. For an adaptive network model, besides the states also the causal relationships can change over time. Table 1 summarises the main concepts of network oriented modelling. The connections indicate the impact that states have on each other. Every connection has a connection weight, which is a numerical value indicating the connection strength. The connections and their weights define the network's connectivity characteristics.

Next to this, every state has a combination functions that describes the manner in which the incoming impacts per connection are combined to form an aggregated impact. This defines the network's aggregation characteristics. A combination function can be a basic combination function from the available Combination Function Library or a weighted average of a number of such basic combination functions. Which combination function is used depends on the application and can also be node-specific. To define the network's timing characteristics, every state has a speed factor that determines how fast a state changes because of its received causal impact. The numerical representation derived from the network characteristics is summarised in Table 2. 
Table 1. An overview of the concepts in the conceptual component of temporal-causal networks.

\begin{tabular}{l|l|l}
\hline Concepts & Notation & Explanation \\
\hline $\begin{array}{l}\text { States and } \\
\text { connections }\end{array}$ & $\begin{array}{l}X, Y \\
X \rightarrow Y\end{array}$ & $\begin{array}{l}\text { Denotes the nodes and edges in the } \\
\text { conceptual representation of a network }\end{array}$ \\
\hline Connection weights & $\boldsymbol{\omega}_{X, Y}$ & $\begin{array}{l}\text { A connection between states } X \text { and } Y \\
\text { has a corresponding connection } \text { weight } \\
\text { In most cases } \omega_{X, Y} \in[-1,1]\end{array}$ \\
\hline Aggregating multiple impacts on a state & $\mathbf{c}_{Y}(.)$. & $\begin{array}{l}\text { Each state has a combination function } \\
\text { and is responsible for combining causal } \\
\text { impacts of all states connected to } Y \text { on } \\
\text { that same state }\end{array}$ \\
\hline Timing of the effect of causal impact & $\eta_{Y}$ & $\begin{array}{l}\text { The speed factor determines how fast a } \\
\text { state is changed by any causal impact. In } \\
\text { most cases: } \eta_{Y} \in[0,1]\end{array}$ \\
\hline
\end{tabular}

Table 2. Numerical representations of temporal-causal networks.

\begin{tabular}{l|l|l}
\hline Concepts & Notation & Explanation \\
\hline State value at time $t$ & $Y(t)$ & $\begin{array}{l}\text { For every time } t \text { a state } Y \\
\text { has a value in }[0,1]\end{array}$ \\
\hline $\begin{array}{l}\text { Single causal impact } \\
\begin{array}{l}\operatorname{impact}_{X, Y}(t) \\
=\omega_{X, Y} X(t)\end{array}\end{array}$ & $\begin{array}{l}\text { At any time } t \text { a state } X \text { (if } \\
\text { connected to } Y \text { ) impacts } Y \\
\text { through a connection weight } \\
\boldsymbol{\omega}_{X, Y}\end{array}$ \\
\hline $\begin{array}{l}\text { Aggregating multiple } \\
\text { impacts on a state }\end{array}$ & $\begin{array}{l}\operatorname{aggimpact}_{Y}(t) \\
=\mathbf{c}_{Y}\left(\operatorname{impact}_{X_{1}, Y}(t), \ldots,\right. \\
\left.\operatorname{impact}_{X_{k}, Y}(t)\right) \\
=\mathbf{c}_{Y}\left(\boldsymbol{\omega}_{X_{1}, Y} X_{1}(t), \ldots, \omega_{X_{k}, Y} X_{k}(t)\right)\end{array}$ & $\begin{array}{l}\text { The combination function } \\
\mathbf{c}_{Y} \text { determines the } \\
\text { aggregated causal impact of } \\
\text { states } X_{i} \text { on } Y\end{array}$ \\
\hline $\begin{array}{l}\text { Timing of the effect of } \\
\text { causal impact }\end{array}$ & $\begin{array}{l}Y(t+\Delta t)=Y(t)+ \\
\eta_{Y}\left[\operatorname{aggimpact}_{Y}(t)-Y(t)\right] \Delta t \\
=Y(t)+ \\
\eta_{Y}\left[\mathbf{c}_{Y}\left(\omega_{X_{1}, Y} X_{1}(t), \ldots, \omega_{X_{k}, Y} X_{k}(t)\right)\right. \\
Y(t)] \Delta t\end{array}$ & $\begin{array}{l}\text { The speed factor } Y \\
\text { determines how fast a state } Y \\
\text { is changed by the aggregated } \\
\text { causal impact of states } X_{i}\end{array}$ \\
\hline
\end{tabular}

The last row of this Table 2, shows the difference equation. Adaptive networks are networks for which some of the characteristics $\omega_{X, Y}, \mathbf{c}_{Y}(.),. \eta_{Y}$ change over time. To model this, extra states are added that represent the adaptive characteristics. For example, for an adaptive connection weight $\boldsymbol{\omega}_{X, Y}$ a new state $\mathbf{W}_{X, Y}$ is added (called a reification state or adaptation state for $\omega_{X, Y}$ ) representing the dynamic value of $\omega_{X, Y}$. 
Table 3 shows an overview of the combination functions used in the designed model. The first is the identity function id(.), which is commonly used when a state only has one incoming connection.

The advanced logistic sum function alogistic $_{\sigma, \tau}(.$.$) is used to aggregate impact for$ each state that has multiple incoming connections; it has as parameters steepness $\sigma$ and threshold $\boldsymbol{\tau}$. The combination function $\mathbf{h e b b}_{\mu}(.$.$) is used for adaptation states \mathbf{W}_{X, Y}$, representing the adaptive value of a connection weight. It has one parameter $\mu$, which is the persistence of the state. In all formula of Table 3 the variables $V_{1}, \ldots, V_{k}$ are used for incoming single impacts, and $W$ for the value of the connection weight reification state.

Table 3. Overview of the combination functions used.

\begin{tabular}{l|l|l}
\hline Combination function & Description & Formula $\mathbf{c}_{Y}\left(V_{1}, \ldots, V_{k}\right)=$ \\
\hline $\mathbf{i d}()$. & Identity & $V$ \\
\hline alogistic $_{\boldsymbol{\sigma}, \tau}(.)$. & Advanced logistic sum & {$\left[\frac{1}{1+\mathrm{e}^{-\sigma\left(V_{1}+\ldots+V_{k}-\tau\right)}}-\frac{1}{\left.1+\mathrm{e}^{\sigma \tau}\right)}\right]\left(1+\mathrm{e}^{-\sigma \tau}\right)$} \\
\hline $\operatorname{hebb}_{\mu}(.)$. & Hebbian learning & $V_{1} V_{2}(1-W)+\mu W$ \\
\hline
\end{tabular}

\section{Modeling Adaptive Burnout Dynamics with Dreams}

This section describes the details of the designed adaptive network model. The states shown in the model are mainly based on the literature mentioned in Sect. 2, specifically [4] and [5]. Table 4 shows the different states that are used in the model, as well as their respective types. There are 5 different state types:

- Protective: Protective states are states that protect a person against a clinical burnout; if they have high values, then the chance of developing a burnout is lower.

- Risk: Risk states are states that increase the chance of developing a burnout.

- Burnout Element: Burnout elements are affected by the protective factors and the risk factors, they are the states that will grow in value when a burnout is developing. Looking at these states is the best way to identify the level of burnout progression.

- Consequent: Consequent states are states that are affected by the burnout elements. By introducing a feedback loop from protective or risk states to burnout elements and then from burnout elements to the protective or risk factors, realistic positive or negative feedback becomes possible. Thus, some states may have a consequent type, as well as another type.

- Dream: The dream type states are newly introduced in this model compared to previous literature on burnout modeling. These dream states regulate the emotions in an adaptive manner as new dream episodes occur, as described in Sect. 2. 
Table 4. The states used in the model and their respective types.

\begin{tabular}{|c|c|c|c|}
\hline State & Abbr. & Description & Type \\
\hline $\mathrm{X}_{1}$ & $\mathrm{CO}$ & Confidence & Protective \\
\hline $\mathrm{X}_{2}$ & $\mathrm{OP}$ & Openness & Protective \\
\hline $\mathrm{X}_{3}$ & $\mathrm{PE}$ & Physical exercise & Protective \\
\hline $\mathrm{X}_{4}$ & $\mathrm{PA}$ & Personal accomplishment & Protective / Consequent \\
\hline $\mathrm{X}_{5}$ & NR & Night rest & Protective / Consequent \\
\hline $\mathrm{X}_{6}$ & $\mathrm{CW}$ & Charged work & Risk \\
\hline $\mathrm{X}_{7}$ & JA & Job ambiguity & Risk \\
\hline $\mathrm{X}_{8}$ & JS & Job satisfaction & Protective / Consequent \\
\hline $\mathrm{X}_{9}$ & $\mathrm{NE}$ & Neuroticism & Risk / Consequent \\
\hline $\mathrm{X}_{10}$ & $\mathrm{SC}$ & Social contact & Protective \\
\hline $\mathrm{X}_{11}$ & EE & Emotional exhaustion & Burnout element \\
\hline $\mathrm{X}_{12}$ & $\mathrm{CY}$ & Cynicism & Burnout element \\
\hline $\mathrm{X}_{13}$ & JP & Job performance & Consequent \\
\hline $\mathrm{X}_{14}$ & JD & Job detachment & Consequent \\
\hline $\mathrm{X}_{15}$ & DU & Drugs & Consequent \\
\hline $\mathrm{X}_{16}$ & ST & Stress & Combination \\
\hline $\mathrm{X}_{17}$ & $\mathrm{fs}_{\mathrm{b}}$ & Feeling state for $b$ & Dream \\
\hline $\mathrm{X}_{18}$ & $\mathrm{SrS}_{\mathrm{ST}}$ & Sensory representation state for ST & Dream \\
\hline $\mathrm{X}_{19}$ & $\mathrm{cs}_{\mathrm{ST}, \mathrm{b}}$ & $\begin{array}{l}\text { Control state for regulation of sensory represen- } \\
\text { tation of ST and feeling b }\end{array}$ & Dream \\
\hline $\mathrm{X}_{20}$ & $\operatorname{des}_{\mathrm{ST}}$ & Dream episode state for ST & Dream \\
\hline $\mathrm{X}_{21}$ & $\mathbf{W}_{\mathrm{srs}, \mathrm{cs}}$ & Reification state for connection weight $\omega_{\text {srsST,csST,b }}$ & Dream \\
\hline $\mathrm{X}_{22}$ & $\mathbf{W}_{\mathrm{fs}, \mathrm{cs}}$ & Reification state for connection weight $\omega_{\mathrm{fsb}, \text { csST,b }}$ & Dream \\
\hline
\end{tabular}

There are two special states shown in Table 4, namely state $X_{21}$ and $X_{22}$. These are the reification states that introduce the adaptivity in the dream component of the model, as described in [7]. These states use a Hebbian combination function, whereas the other states all use a logistic function. Furthermore, state $\mathrm{X}_{16}$ has a type 'combination', which was not mentioned above. According to [1], the main symptom of a clinical burnout is the high stress level. Stress is an abstract concept that can be approached using multiple emotions mentioned in Sect. 2. The stress state was added to the model as a kind of aggregate state that represents an overall combination of some other important states in the model. The stress state is not directly regulated; instead states $\mathrm{X}_{17}$ and $\mathrm{X}_{18}$ corresponding to the feeling state of stress and the sensory representation of stress are regulated by the Control state $\mathrm{X}_{19}$. A conceptual representation of the introduced adaptive network model is shown in Fig. 2. This Fig. 2 shows two planes, of which the second plane (blue) represents the adaptation states in the network: state $X_{21}$ and $X_{22}$ represent the values for the weights of the connections from state $X_{17}$ to state $X_{19}$ and from state $\mathrm{X}_{18}$ to state $\mathrm{X}_{19}$, which allows the connection weight values to change over time. In contrast to the simplified representation shown in Fig. 2, the actual model contains many more causal relations between all states, as most emotions slightly affect each other, as 
shown in literature and mentioned in Sect. 2. The network characteristics for connectivity (the connections and their weights), aggregation (the combination functions and their parameters), and timing (the speed factors) have been specified in the form of role matrices, which provides a compact specification format for (adaptive) temporal-causal network models. For two of them, mb (base matrix) and mcw (matrix for connection weights) specifying the connectivity characteristics, see Box 1.

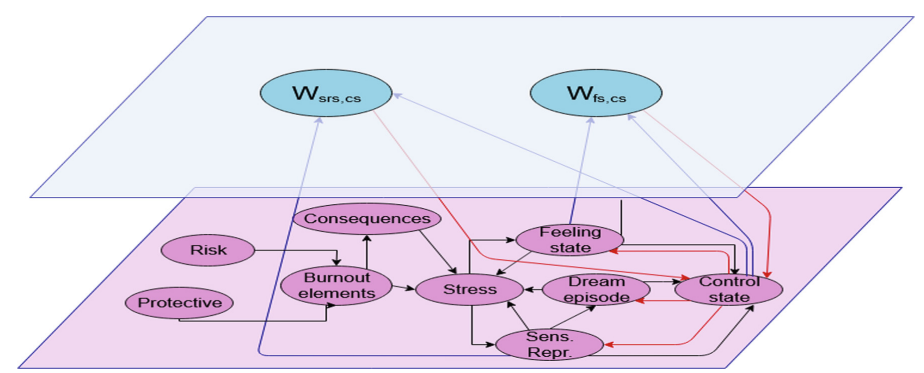

Fig. 2. A simplified conceptual representation of the designed first-order adaptive temporal-causal network. The upper plane indicates the adaptiveness of the model. (Color figure online)

Most of the values for these network characteristics were selected based on empirical data as well as previous works like [4] and [5]. Role matrices have rows for all the states and at each row indicate the elements that for the specific role have impact on that state. For example, in Box 1 in $\mathbf{~ m b}$ it is indicated which other states have basic impact, and in mow it is indicated what is the connection weight impact for that state. Note that the cells with nonadaptive values are green and the cells with adaptive values are red. In the latter cells, not a value but the name of the reification state is specified which represents the adaptive value. This can be seen in the row for the control state $X_{19}$, where $X_{21}$ and $\mathrm{X}_{22}$ are indicated as the states representing the adaptive values. 


\begin{tabular}{|c|c|c|c|c|c|c|c|c|c|c|c|c|c|}
\hline \multirow{2}{*}{\multicolumn{2}{|c|}{\begin{tabular}{|c|}
$\mathbf{m b}$ \\
State Abbr \\
\end{tabular}}} & \multirow{2}{*}{1} & \multirow{2}{*}{2} & \multirow{2}{*}{3} & \multirow{2}{*}{4} & \multirow{2}{*}{5} & \multirow{2}{*}{6} & \multirow{2}{*}{7} & \multirow{2}{*}{8} & \multirow{2}{*}{9} & \multirow{2}{*}{10} & \multirow{2}{*}{11} & \multirow{2}{*}{12} \\
\hline & & & & & & & & & & & & & \\
\hline $\mathrm{X}_{1}$ & $\mathrm{CO}$ & $\mathrm{PE}$ & PA & JA & JS & NE & JP & JD & & & & & \\
\hline $\mathrm{X}_{2}$ & OP & $\mathrm{CO}$ & PE & JS & $\mathrm{NE}$ & SC & JD & & & & & & \\
\hline $\mathrm{X}_{3}$ & $\mathrm{PE}$ & OP & & & & & & & & & & & \\
\hline $\mathrm{X}_{4}$ & PA & $\mathrm{CO}$ & $\mathrm{PA}$ & $\mathrm{CW}$ & JA & JS & $\mathrm{NE}$ & $\mathrm{EE}$ & JP & JD & & & \\
\hline $\mathrm{X}_{5}$ & NR & $\mathrm{PE}$ & $\mathrm{PA}$ & $\mathrm{CW}$ & JS & $\mathrm{NE}$ & $\mathrm{EE}$ & DU & & & & & \\
\hline $\mathrm{X}_{6}$ & $\mathrm{CW}$ & $\mathrm{CO}$ & $\mathrm{PE}$ & PA & NR & $\mathrm{CW}$ & JA & JS & $\mathrm{NE}$ & $\mathrm{SC}$ & $\mathrm{EE}$ & JD & $\overline{\mathrm{DU}}$ \\
\hline $\mathrm{X}_{7}$ & JA & $\mathrm{CO}$ & PA & NR & JA & JS & $\mathrm{NE}$ & $\mathrm{SC}$ & EE & JD & DU & & \\
\hline $\mathrm{X}_{8}$ & JS & $\mathrm{PA}$ & $\mathrm{CW}$ & JA & $\mathrm{NE}$ & $\mathrm{EE}$ & $\mathrm{CY}$ & JP & JD & & & & \\
\hline $\mathrm{X}_{9}$ & $\mathrm{NE}$ & $\mathrm{CO}$ & $\mathrm{OP}$ & $\mathrm{PE}$ & PA & NR & $\mathrm{CW}$ & $\mathrm{JA}$ & JS & $\mathrm{SC}$ & $\mathrm{EE}$ & JP & JD \\
\hline $\mathrm{X}_{10}$ & SC & $\mathrm{CO}$ & OP & PE & NR & $\mathrm{NE}$ & & & & & & & \\
\hline $\mathrm{X}_{11}$ & EE & $\mathrm{CO}$ & OP & NR & $\mathrm{CW}$ & JA & JS & $\mathrm{NE}$ & JP & JD & DU & & \\
\hline $\mathrm{X}_{12}$ & $\mathrm{CY}$ & $\mathrm{CO}$ & OP & $\mathrm{NE}$ & $\mathrm{EE}$ & JD & & & & & & & \\
\hline $\mathrm{X}_{13}$ & JP & $\mathrm{CO}$ & PA & NR & $\mathrm{CW}$ & JA & JS & $\mathrm{NE}$ & $\mathrm{SC}$ & $\mathrm{EE}$ & JD & $\mathrm{DU}$ & \\
\hline $\mathrm{X}_{14}$ & JD & $\mathrm{CO}$ & PA & $\mathrm{CW}$ & JA & JS & $\mathrm{NE}$ & $\mathrm{EE}$ & $\mathrm{CY}$ & $\mathrm{JP}$ & $\mathrm{DU}$ & & \\
\hline $\mathrm{X}_{15}$ & DU & OP & $\mathrm{PE}$ & $\mathrm{CW}$ & $\mathrm{NE}$ & SC & $\mathrm{EE}$ & DU & & & & & \\
\hline $\mathrm{X}_{16}$ & ST & $\mathrm{EE}$ & $\mathrm{CY}$ & JP & JD & & & & & & & & \\
\hline $\mathrm{X}_{17}$ & $\mathrm{fs}_{\mathrm{b}}$ & ST & $\mathrm{cs}_{\mathrm{st}, \mathrm{b}}$ & & & & & & & & & & \\
\hline $\mathrm{X}_{18}$ & srs $_{\mathrm{ST}}$ & ST & $\mathrm{cs}_{\mathrm{st}, \mathrm{b}}$ & & & & & & & & & & \\
\hline $\mathrm{X}_{19}$ & $\mathrm{cs}_{\mathrm{ST}, \mathrm{b}}$ & $\mathrm{fs}_{\mathrm{b}}$ & srs $_{\mathrm{st}}$ & $\operatorname{des}_{\mathrm{st}}$ & & & & & & & & & \\
\hline $\mathrm{X}_{20}$ & $\operatorname{des}_{\mathrm{ST}}$ & $\mathrm{srS}_{\mathrm{st}}$ & $\mathrm{cs}_{\mathrm{st}, \mathrm{b}}$ & & & & & & & & & & \\
\hline $\mathrm{X}_{21}$ & $\mathbf{W}_{\mathrm{srs}, \mathrm{cs}}$ & $\mathrm{srS}_{\mathrm{st}}$ & $\mathrm{cs}_{\mathrm{st}, \mathrm{b}}$ & $\mathbf{W}_{\mathrm{srs}, \mathrm{cs}}$ & & & & & & & & & \\
\hline $\mathrm{X}_{22}$ & $\mathbf{W}_{\mathrm{fs}, \mathrm{cs}}$ & $\mathrm{fs}_{\mathrm{b}}$ & $\mathrm{cs}_{\mathrm{st}, \mathrm{b}}$ & $\mathbf{W}_{\mathrm{fs}, \mathrm{cs}}$ & & & & & & & & & \\
\hline \multicolumn{2}{|c|}{ mcw } & 1 & 2 & 3 & 4 & 5 & 6 & 7 & 8 & 9 & 10 & 11 & 12 \\
\hline \multicolumn{2}{|c|}{ State Abbr } & 1 & 2 & 3 & 4 & 5 & 0 & 1 & 0 & 9 & 10 & 11 & 12 \\
\hline $\mathrm{X}_{1}$ & $\mathrm{CO}$ & 0.5 & 1 & -1 & 1 & -1 & 1 & -0.5 & & & & & \\
\hline $\mathrm{X}_{2}$ & OP & 1 & 0.5 & 1 & -1 & 1 & -0.5 & & & & & & \\
\hline $\mathrm{X}_{3}$ & $\mathrm{PE}$ & 1 & & & & & & & & & & & \\
\hline $\mathrm{X}_{4}$ & PA & 1 & 1 & -0.5 & -1 & 1 & -1 & -0.5 & 1 & -1 & & & \\
\hline $\mathrm{X}_{5}$ & NR & 0.5 & 0.25 & -1 & 1 & -0.5 & -0.5 & 1 & & & & & \\
\hline $\mathrm{X}_{6}$ & $\mathrm{CW}$ & -1 & -0.5 & -0.5 & -1 & 0.5 & 1 & -1 & 1 & -0.5 & 1 & -1 & 1 \\
\hline $\mathrm{X}_{7}$ & JA & -1 & -1 & -1 & 1 & -1 & 1 & -0.5 & 1 & -1 & -1 & & \\
\hline $\mathrm{X}_{8}$ & JS & 1 & -1 & -1 & -1 & -1 & -0.5 & 1 & -1 & & & & \\
\hline $\mathrm{X}_{9}$ & $\mathrm{NE}$ & -0.25 & -0.25 & -0.25 & -0.5 & -0.5 & 1 & 1 & -0.5 & -0.5 & 1 & -0.5 & 1 \\
\hline $\mathrm{X}_{10}$ & $\mathrm{SC}$ & 1 & 1 & 0.5 & 0.5 & -1 & & & & & & & \\
\hline $\mathrm{X}_{11}$ & EE & -0.5 & -1 & -1 & 1 & 1 & -1 & 1 & \begin{tabular}{|l|}
-0.25 \\
\end{tabular} & -1 & -0.5 & & \\
\hline $\mathrm{X}_{12}$ & $\mathrm{CY}$ & 0.25 & -1 & 0.5 & 0.25 & 1 & & & & & & & \\
\hline $\mathrm{X}_{13}$ & JP & 1 & 1 & 1 & -0.5 & -0.75 & 1 & -1 & 0.25 & -0.5 & -1 & -1 & \\
\hline $\mathrm{X}_{14}$ & JD & -0.5 & -1 & -1 & 1 & -1 & 1 & 1 & 1 & -0.5 & 0.25 & & \\
\hline $\mathrm{X}_{15}$ & DU & 0.25 & -0.5 & \begin{tabular}{|l|}
0.25 \\
\end{tabular} & 1 & 0.25 & 0.25 & 0.5 & & & & & \\
\hline $\mathrm{X}_{16}$ & ST & 1 & 1 & -1 & 1 & & & & & & & & \\
\hline $\mathrm{X}_{17}$ & $f_{s_{b}}$ & 1 & -1 & & & & & & & & & & \\
\hline $\mathrm{X}_{18}$ & $\mathrm{srS}_{\mathrm{ST}}$ & 0.5 & -1 & & & & & & & & & & \\
\hline $\mathrm{X}_{19}$ & $\mathrm{cS}_{\mathrm{ST}, \mathrm{b}}$ & $\mathrm{X}_{22}$ & $X_{21}$ & 0.3 & & & & & & & & & \\
\hline $\mathrm{X}_{20}$ & $\operatorname{des}_{\mathrm{ST}}$ & 1 & -1 & & & & & & & & & & \\
\hline $\mathrm{X}_{21}$ & $\mathbf{W}_{\mathrm{sr}, \mathrm{cs}}$ & 1 & 1 & 1 & & & & & & & & & \\
\hline $\mathrm{X}_{22}$ & $\mathbf{W}_{\mathrm{fs}, \mathrm{cs}}$ & 1 & 1 & 1 & & & & & & & & & \\
\hline
\end{tabular}

Box 1 Role matrices for the connectivity characteristics: role matrix mb (base connectivity) and role matrix mcw (connection weights).

Similarly, in Box 2 a role matrix ms (matrix for speed factors) specifies what speed factor value has impact on the state, role matrix mcfw (matrix for combination function weights) specifies what combination function weights have impact and mcfp (matrix for combination function parameters) what parameter values of the combination function. As can be seen in these role matrices, no further adaptive characteristics were considered. 


\begin{tabular}{|c|c|c|c|c|c|c|c|c|c|c|c|c|}
\hline \multirow{3}{*}{\multicolumn{2}{|c|}{\begin{tabular}{|c|} 
mcfw \\
State Abbr \\
\end{tabular}}} & \multirow{3}{*}{ hebb } & \multirow{3}{*}{ alogistic } & \multicolumn{2}{|c|}{ mefp } & \multicolumn{2}{|c|}{ hebb } & \multicolumn{2}{|c|}{ alogistic } & \multirow{2}{*}{\multicolumn{2}{|c|}{$\mathbf{m s}$}} & \multirow{3}{*}{1} \\
\hline & & & & \multirow{2}{*}{\multicolumn{2}{|c|}{ State Abbr }} & \multirow{2}{*}{$\begin{array}{l}1 \\
\mu\end{array}$} & \multirow[t]{2}{*}{2} & \multirow{2}{*}{$\begin{array}{l}1 \\
\sigma\end{array}$} & \multirow{2}{*}{$\begin{array}{l}2 \\
\tau\end{array}$} & & & \\
\hline & & & & & & & & & & State & Abbr & \\
\hline$X_{1}$ & $\mathrm{CO}$ & & 1 & $\mathrm{X}_{1}$ & $\mathrm{CO}$ & & & 50 & 0.5 & $\mathrm{X}_{1}$ & $\mathrm{CO}$ & 0.1 \\
\hline $\mathrm{X}_{2}$ & OP & & 1 & $\mathrm{X}_{2}$ & OP & & & 50 & 0.5 & $\mathrm{X}_{2}$ & OP & 0.1 \\
\hline $\mathrm{X}_{3}$ & $\mathrm{PE}$ & & 1 & $X_{3}$ & $\mathrm{PE}$ & & & 50 & 0.5 & $\mathrm{X}_{3}$ & $\mathrm{PE}$ & 0.1 \\
\hline $\mathrm{X}_{4}$ & PA & & 1 & $\mathrm{X}_{4}$ & PA & & & 50 & 0.5 & $\mathrm{X}_{4}$ & $\mathrm{PA}$ & 0.1 \\
\hline $\mathrm{X}_{5}$ & NR & & 1 & $\mathrm{X}_{5}$ & NR & & & 50 & 0.5 & $\mathrm{X}_{5}$ & NR & 0.1 \\
\hline $\mathrm{X}_{6}$ & $\mathrm{CW}$ & & 1 & $\mathrm{X}_{6}$ & $\mathrm{CW}$ & & & 50 & 0.5 & $\mathrm{X}_{6}$ & $\mathrm{CW}$ & 0.1 \\
\hline $\mathrm{X}_{7}$ & $\mathrm{JA}$ & & 1 & $\mathrm{X}_{7}$ & $\mathrm{JA}$ & & & 50 & 0.5 & $\mathrm{X}_{7}$ & $\mathrm{JA}$ & 0.1 \\
\hline $\mathrm{X}_{8}$ & JS & & 1 & $\mathrm{X}_{8}$ & JS & & & 50 & 0.5 & $\mathrm{X}_{8}$ & JS & 0.1 \\
\hline $\mathrm{X}_{9}$ & $\mathrm{NE}$ & & 1 & $\mathrm{X}_{9}$ & $\mathrm{NE}$ & & & 50 & 0.5 & $\mathrm{X}_{9}$ & $\mathrm{NE}$ & 0.1 \\
\hline $\mathrm{X}_{10}$ & $\mathrm{SC}$ & & 1 & $\mathrm{X}_{10}$ & SC & & & 50 & 0.5 & $\mathrm{X}_{10}$ & $\mathrm{SC}$ & 0.1 \\
\hline $\mathrm{X}_{11}$ & $\mathrm{EE}$ & & 1 & $\mathrm{X}_{11}$ & $\mathrm{EE}$ & & & 50 & 0.5 & $\mathrm{X}_{11}$ & $\mathrm{EE}$ & 0.1 \\
\hline $\mathrm{X}_{12}$ & $\mathrm{CY}$ & & 1 & $\mathrm{X}_{12}$ & $\mathrm{CY}$ & & & 50 & 0.5 & \begin{tabular}{|l|}
$\mathrm{X}_{12}$ \\
\end{tabular} & $\mathrm{CY}$ & 0.1 \\
\hline $\mathrm{X}_{13}$ & JP & & 1 & $\mathrm{X}_{13}$ & JP & & & 50 & 0.5 & $\mathrm{X}_{13}$ & JP & 0.1 \\
\hline $\mathrm{X}_{14}$ & JD & & 1 & $\mathrm{X}_{14}$ & JD & & & 50 & 0.5 & $\mathrm{X}_{14}$ & JD & 0.1 \\
\hline $\mathrm{X}_{15}$ & $\mathrm{DU}$ & & 1 & $\mathrm{X}_{15}$ & DU & & & 50 & 0.5 & $\mathrm{X}_{15}$ & DU & 0.1 \\
\hline $\mathrm{X}_{16}$ & ST & & 1 & $\mathrm{X}_{16}$ & ST & & & 50 & 0.5 & $\mathrm{X}_{16}$ & ST & 0.1 \\
\hline$X_{17}$ & $\mathrm{fs}_{\mathrm{b}}$ & & 1 & $X_{17}$ & $\mathrm{fs}_{\mathrm{b}}$ & & & 50 & 0.5 & $\mathrm{X}_{17}$ & $\mathrm{fs}_{\mathrm{b}}$ & 0.1 \\
\hline $\mathrm{X}_{18}$ & $\mathrm{srS}_{\mathrm{ST}}$ & & 1 & $\mathrm{X}_{18}$ & \begin{tabular}{|l|}
$\mathrm{srS}_{\mathrm{ST}}$ \\
\end{tabular} & & & 50 & 0.1 & \begin{tabular}{|l|}
$\mathrm{X}_{18}$ \\
\end{tabular} & $\mathrm{srs}_{\mathrm{ST}}$ & 0.1 \\
\hline $\mathrm{X}_{19}$ & $\mathrm{cS}_{\mathrm{ST}, \mathrm{b}}$ & & 1 & $\mathrm{X}_{19}$ & $\mathrm{cS}_{\mathrm{ST}, \mathrm{b}}$ & & & 50 & 0.5 & $\mathrm{X}_{19}$ & $\mathrm{cS}_{\mathrm{ST}, \mathrm{b}}$ & 0.1 \\
\hline $\mathrm{X}_{20}$ & $\operatorname{des}_{\mathrm{ST}}$ & & 1 & $\mathrm{X}_{20}$ & $\operatorname{des}_{\mathrm{ST}}$ & & & 60 & 0.25 & $\begin{array}{l}X_{20} \\
\end{array}$ & $\operatorname{des}_{\mathrm{ST}}$ & 0.1 \\
\hline $\mathrm{X}_{21}$ & $\mathbf{W}_{\mathrm{srs}, \mathrm{cs}}$ & 1 & & $\mathrm{X}_{21}$ & $\mathbf{W}_{\mathrm{srs}, \mathrm{cs}}$ & 0.99 & & & & $\mathrm{X}_{21}$ & $\mathbf{W}_{\mathrm{srs}, \mathrm{cs}}$ & 1 \\
\hline \begin{tabular}{|l|}
$X_{22}$ \\
\end{tabular} & $\mathbf{W}_{\mathrm{fs}, \mathrm{cs}}$ & 1 & & $\mathrm{X}_{22}$ & $\mathbf{W}_{\mathrm{fs}, \mathrm{cs}}$ & 0.99 & & & & \begin{tabular}{|l|}
$\mathrm{X}_{22}$ \\
\end{tabular} & $\mathbf{W}_{\mathrm{fs}, \mathrm{cs}}$ & 1 \\
\hline
\end{tabular}

Box 2 Role matrices for the aggregation characteristics: role matrix mefw (combination function weights) and role matrix mcfp (combination function parameter values); and role matrix for the timing characteristics: role matrix ms (speed factors).

\section{Simulation Results}

This section shows the results obtained by running the model described in Sect. 4. The model was simulated using the modeling environment described in [14] and [8], Ch 9, using different initial values to create different scenarios. This modeling environment uses the above role matrices and initial values (and the step size $\Delta t$ and end time of the simulation) as input and then runs the simulations. These scenarios were tested to gain a better understanding of the model and of clinical burnout progression. The main scenarios tested are non-burnout versus burnout scenarios, which are obtained by proper setting of the initial values of the relevant protective and risk states. Due to the many causal relationships, initial values can severely impact the outcome of the simulation. The scenarios were obtained by using the initial values for the states shown in Table 5 and $\Delta t=0.01$. Figure 3 shows the progression of the states for a non-burnout scenario (left) and a burnout scenario (right). For the non-burnout scenario the initial values of the states that form high risks are low and the protective factors are high, as can be seen in Table 5. The lines in the figure are colored based on their type: protective factors in green, risk factors yellow, burnout elements red, consequences blue, dream factors magenta, and finally, the stress state in black. The difference between states that share the same type is shown using different line styles.

The pattern can be explained by looking at where the states are converging to. The protective factors are converging to one (all had high initial values), while the risk factors converge to zero and (they had low initial values). 
Table 5. The initial values used for the non-burnout and burnout scenarios.

\begin{tabular}{l|l|l|l|l|l|l|l|l|l|l}
\hline State & $\mathrm{X}_{1}$ & $\mathrm{X}_{2}$ & $\mathrm{X}_{3}$ & $\mathrm{X}_{4}$ & $\mathrm{X}_{5}$ & $\mathrm{X}_{6}$ & $\mathrm{X}_{7}$ & $\mathrm{X}_{8}$ & $\mathrm{X}_{9}$ & $\mathrm{X}_{10}$ \\
\hline Non-burnout & 0.85 & 0.80 & 0.70 & 0.75 & 0.72 & 0.21 & 0.15 & 0.75 & 0.10 & 0.82 \\
\hline Burnout & 0.25 & 0.22 & 0.23 & 0.20 & 0.35 & 0.90 & 0.95 & 0.30 & 0.98 & 0.17 \\
\hline State & $\mathrm{X}_{12}$ & $\mathrm{X}_{13}$ & $\mathrm{X}_{14}$ & $\mathrm{X}_{15}$ & $\mathrm{X}_{16}$ & $\mathrm{X}_{17}$ & $\mathrm{X}_{18}$ & $\mathrm{X}_{19}$ & $\mathrm{X}_{20}$ & $\mathrm{X}_{21}$ \\
\hline Non-burnout & 0.20 & 0.78 & 0.15 & 0.22 & 0.00 & 0.00 & 0.00 & 0.00 & 0.00 & 0.00 \\
\hline Burnout & 0.15 & 0.90 & 0.05 & 0.075 & 0.00 & 0.00 & 0.00 & 0.00 & 0.00 & 0.50 \\
\hline
\end{tabular}
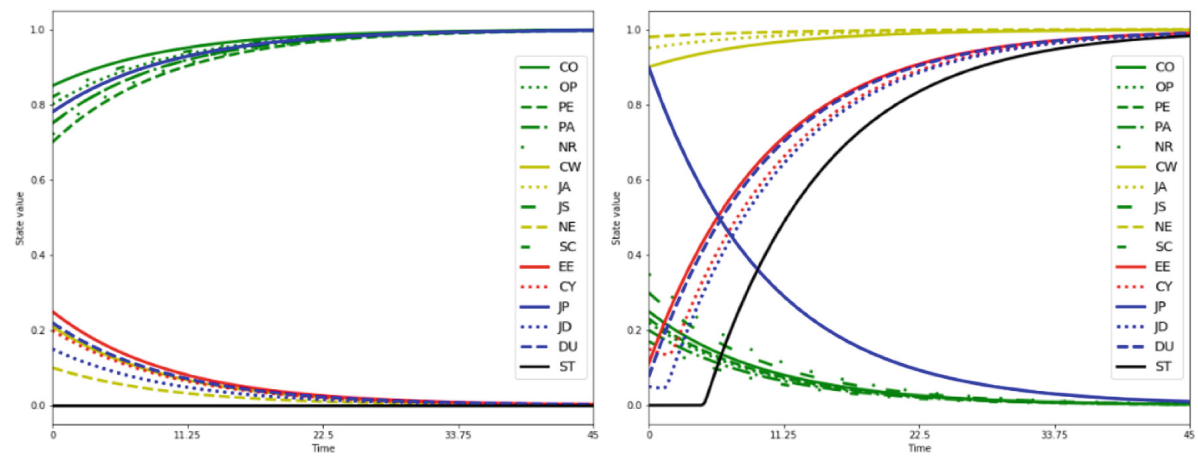

Fig. 3. Non-burnout scenario (left) and a burnout scenario (right) simulated, all states except the dream states are shown. States are colored by their type and can be distinguished by looking at their line types. (Color figure online)

When the initial values are changed to the values noted in the burnout scenario rows in Table 5, the plot shown in the right hand side of Fig. 3 is acquired. This graph is a bit more complex compared to the left graph, as more dynamics are shown. The figure shows how the protective states, which have low initial values, converge to zero this time. In contrast, the risk states, with high initial values, converge to one. This has multiple repercussions for the model, as can be seen from the burnout element states (red), EE and CY. As the burnout element states start to increase in value, the consequent states (blue) are affected. For example, the job performance state, which had an initial value of 0.90 , starts to converge to zero, even though it had a high initial value. Next to this, the consequent states job detachment and drugs, start to converge to one, which starts to indicate the condition of the simulated person. Finally, the black line shows the stress factor, which is a combination of the most important stress-related states. At first, the stress level is not changing, until a tipping point is reached where it starts to converge to one, as the consequent states are starting to affect the stress level too much compared to the protective factors.

Figure 4 shows the progression of the dream states during the burnout scenario simulation. The dream states are not shown in Fig. 3 to prevent the figure from becoming unreadable. The brown and purple lines in Fig. 4 indicate the reification states that show the progression of the adaptive weights from the sensory representation state of stress 
to the control state and the feeling state to the control state. The reification states are affected by the control state, their own state, and respectively the sensory representation state and feeling state. This can also be seen in Fig. 4, as the reification state $\mathbf{W}_{\text {srs,cs }}$ starts to increase when the control state as well as the sensory representation are increasing and then starts to slowly decrease when the sensory representation state converges to zero. The reification states increase due to the fear extinction learning cycle [7], which means that when the connections are used more, they are strengthened over time. Furthermore, the sensory representation state starts to increase rapidly, but when the control state starts to increase, the sensory representation state starts to decrease, until it converges all the way to zero. This is due to the negative emotion regulation cycle, where the control state affects the feeling state and sensory representation state as well as the dream episode state [7]. Dream episodes are generated by the sensory representation state, which affects the control state as well. This simulation includes one dream episode, which can be seen from the red line, that peaks around $t=20$ and then converges to zero.

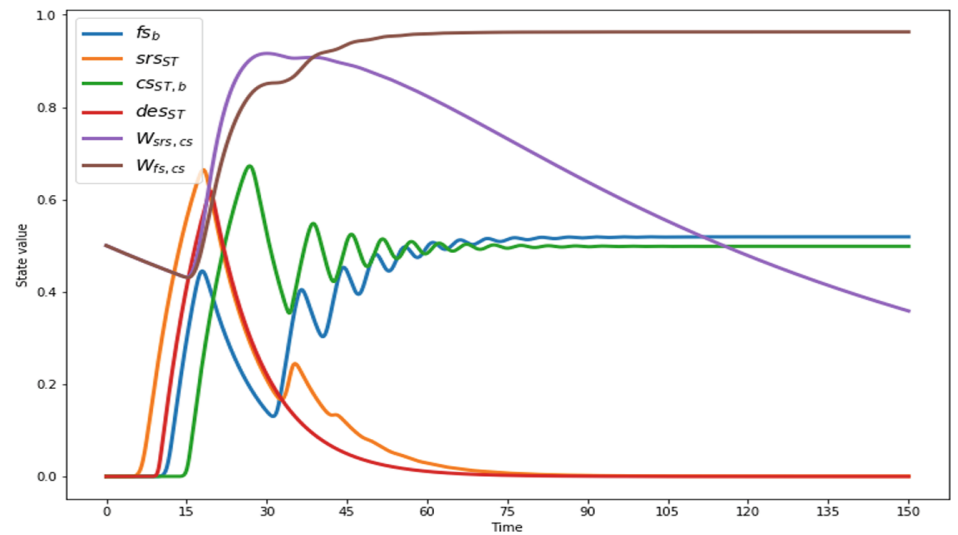

Fig. 4. A display of the change in the dream states values during the burnout scenario simulation. (Color figure online)

The interesting part of the figure, is where in contrast to the sensory representation of stress, the feeling state starts to increase and then decrease, which is in line with literature and the expected behavior, but then starts to increase again due to the resonance with the control state. At that point, both the control state and the feeling state of stress are resonating with one another and are creating a cycle where they are both enforcing the behavior of each other. This continues until the feeling state $\mathrm{fs}_{\mathrm{b}}$ reaches a point where its value is higher than the value of the control state, after this they converge to their respective values.

\section{Empirical Validation}

Although no numerical empirical data is available that outlines the exact influence that emotions have on one another in a quantified manner, certain patterns can still be found 
in the literature, which can be used to validate the model in an empirical manner. This section will describe how the network model's characteristics were tuned in accordance with the patterns found in literature. In [4] and [5], the models were tuned in accordance with respectively physical exercise and sleep components, which allowed for a more realistic selection of parameter values.

This paper tunes the most important dream states, the feeling state and the control state, in accordance with the patterns found in [7, 15-17]. This was done by first creating data points in a manner that corresponds with the noted literature. The data points used can be found in Table 6 . The pattern that would be acquired by tuning the parameters to be in accordance with the data points, would be more in line with the emotion regulation cycle, instead of the resonance pattern that was shown in Fig. 4. The network characteristics that were selected to be tuned as parameters were the connection weights for the incoming connections to the feeling state $X_{17}$ and the control state $X_{19}$, making 5 parameters in total.

To tune the parameters, a simulated annealing algorithm was used with the default settings of Matlab's Optimization Toolkit. A final Root Mean Squared Error (RMSE) of $9.87 * 10^{-2}$ was acquired using $10^{4}$ iterations. Table 7 shows the optimal values that were found to achieve the RMSE in accordance with Table 6. After simulating the model, using the initial values for the burnout scenario shown in Table 5, it can be seen that the results are more in accordance with literature, as shown in Fig. 5.

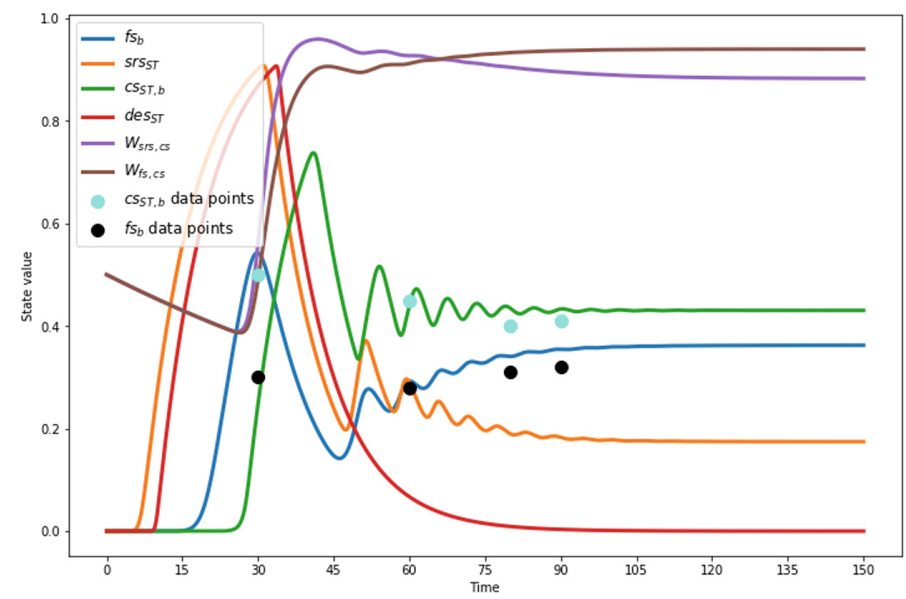

Fig. 5. Burnout scenario simulation using the optimal parameters found in Table 7 with the initial values shown in Table 5 compared to the empirical data as dots.

Extinction learning and the reduction in feeling level can now be properly shown in accordance with [5]. The resonance is still present, but in contrast to Fig. 4, the feeling state does not surpass the control state, as they both converge before intersecting a second time. The Appendix (see https://www.researchgate.net/publication/340162256) shows the development of the RMSE over iterations during the tuning process. 
Table 6. Data points created for the feeling state and control state in accordance with patterns found in literature.

\begin{tabular}{l|l|l}
\hline Time & $\mathrm{fs}_{\mathrm{b}}$ & $\mathrm{cs}_{S T, \mathrm{~b}}$ \\
\hline 30 & 0.50 & 0.30 \\
\hline 60 & 0.45 & 0.28 \\
\hline 80 & 0.40 & 0.31 \\
\hline 99 & 0.38 & 0.30 \\
\hline
\end{tabular}

Table 7. Optimal parameter values found for network characteristics $\omega_{\mathbf{S T}, \mathbf{f} \mathbf{s}_{\mathbf{b}}}, \boldsymbol{\omega}_{\mathbf{c s}_{\mathbf{S T}, \mathbf{b}}, \mathbf{f} \mathbf{s}_{\mathbf{b}}}$ and

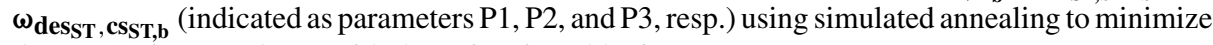
the RMSE in accordance with the points in Table 6.

\begin{tabular}{l|l|l}
\hline$\omega_{\mathbf{S T}, \mathbf{f s}_{\mathbf{b}}}$ & $\boldsymbol{\omega}_{\mathbf{C S S}_{\mathbf{S T}, \mathbf{b}}, \mathbf{f S}_{\mathbf{b}}}$ & $\boldsymbol{\omega}_{\mathbf{d e s}_{\mathbf{S T}}, \mathbf{c s} \mathbf{S T}, \mathbf{b}}$ \\
\hline $\mathrm{P} 1$ & $\mathrm{P} 2$ & $\mathrm{P} 3$ \\
\hline 0.632 & -0.333 & -0.037 \\
\hline
\end{tabular}

\section{Mathematical Verification}

The methods to verify if a model is mathematically correct described in [7] and [8] were followed by checking some of the stationary points for the states. Stationary points can be identified when $\mathrm{d} Y(t) / \mathrm{d} t=0$. Given the formulae in Sect. 3, a criterion for finding a stationary point, is whether $\operatorname{aggimpact}_{Y}(t)=Y(t)$ holds, or $\mathbf{c}_{Y}\left(\omega_{X_{1}, Y} X_{1}(t)\right.$, $\left.\ldots, \omega_{X_{k}, Y} X_{k}(t)\right)=Y(t)$. This criterion can thus be used to identify stationary points in a temporal-causal network. This was done for the burnout scenario described in Sect. 5.

The model was run until $t=100$ and then state $\mathrm{fs}_{\mathrm{b}}$ and state srs $\mathrm{ST}_{\mathrm{S}}$ were analysed to see if they reached stationary points, by plotting the gradient of the states and finding the points where the gradient is 0 . The result can be seen in Fig. 6, which yields some of the points that have been noted in Table 8 for analysis usable for mathematical verification. To estimate the correctness of the model, four points for two states (for each of the two states two different time points) were analysed; the average error for the points as shown in Table 8 is $2.855 * 10^{-4}$, which is a small error and is an indication of evidence that the model is mathematically accurate.

The errors were acquired by calculating the difference between the state values $\mathrm{X}_{i}(t)$ and aggimpact $_{\mathrm{X}_{i}}(t)$, which is based on the logistic combination function with as input the incoming state values with their corresponding weights, with $\sigma=50$ and $\tau=0.5$ for state $X_{17}$ and $\tau=0.1$ for state $X_{18}$. 
Table 8. Stationary point identification to verify the model.

\begin{tabular}{l|l|l|l|l}
\hline State $\mathrm{X}_{i}$ & $\mathrm{fs}_{\mathrm{b}}=\mathrm{X}_{17}$ & $\mathrm{fs}_{\mathrm{b}}=\mathrm{X}_{17}$ & $\begin{array}{l}\mathrm{srs}_{\mathrm{ST}}= \\
\mathrm{X}_{18}\end{array}$ & $\begin{array}{l}\mathrm{srs}_{\mathrm{ST}}= \\
\mathrm{X}_{18}\end{array}$ \\
\hline Time point $t$ & 17.94 & 31.19 & 18.14 & 32.73 \\
\hline $\mathrm{X}_{i}(t)$ & 0.4449 & 0.1303 & 0.6643 & 0.1665 \\
\hline aggimpact $\mathrm{X}_{i}(t)$ & 0.4446 & 0.1305 & 0.6648 & 0.1665 \\
\hline deviation & $3 * 10^{-4}$ & $2.5 * 10^{-4}$ & $\begin{array}{l}5.1 * \\
10^{-4}\end{array}$ & $\begin{array}{l}8.2 * \\
10^{-5}\end{array}$ \\
\hline
\end{tabular}

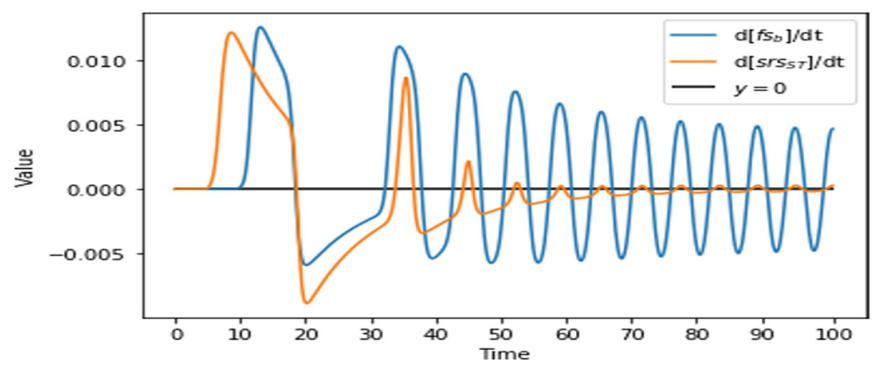

Fig. 6. Plot of the gradient (derivative over time) of states $f_{s_{b}}$ and srsst to identify where intersections are with $y=0$, which indicate stationary points.

\section{Discussion}

The goal of this study was to design an adaptive temporal-causal network model incorporating dream components to create adaptive and more realistic burnout dynamics than in earlier models $[4,5]$. Not only dream states were added, the model was also turned into a first-order adaptive model using a hebbian learning approach for adaptive weights between states involved in dreaming. Using the methodology described in $[7,8]$ and the environment described in [14], a model was created that can be simulated as well as optimised. The results acquired by introducing dream states, do substantially differ from previous work that only introduced states corresponding to sleep [5], as dreams are powerful regulators of emotions such as fear [17].

Further application of the model may address a portrayal of how a clinical burnout might develop, as this might give more insights into how they can be prevented. This could be done for example, by creating an agent-based model, that keeps track of the emotional wellbeing of a person and then scheduling them in manners where they gain enough sleep which allows for enough dreams to take place, to prevent them from developing burnouts. One issue is still that there is no numerical data available, which means that the model had to be validated based on qualitative empiric information using a simulated annealing algorithm to tune parameters to find the behavior of the model that is in accordance with the literature.

This paper serves as a first step to create an adaptive temporal-causal network describing burnout dynamics, which can still be expanded in the future, by adding more real-life 
states. If more empirical data becomes available in regard to burnout, it will also become possible to optimise the relationships between states, that were now based on qualitative literature. When these components are optimised, a foundation can be created to prevent, treat, or identify burnouts as well as gain a better understanding of the underlying dynamics.

\section{References}

1. Burn-out an "occupational phenomenon": International Classification of Diseases. WHO

2. CBS, TNO: Psychosociale arbeidsbelasting (PSA) werknemers (2017). http://statline.cbs.nl/ StatWeb/publiction/?VW=T\&DM=SLNL\&PA=83049NED\&LA=NL

3. CBS: Meer psychische vermoeidheid ervaren door werk (2018). https://www.cbs.nl/nl-nl/nie uws/2018/46/meer-psychische-vermoeidheid-ervaren-door-werk

4. Dujmić, Z., Machielse, E., Treur, J.: A temporal-causal modeling approach to the dynamics of a burnout and the role of physical exercise. In: Samsonovich, A.V. (ed.) BICA 2018. AISC, vol. 848, pp. 88-100. Springer, Cham (2019). https://doi.org/10.1007/978-3-319-99316-4_12

5. von Kentzinsky, H., Wijtsma, S., Treur, J.: A temporal-causal modelling approach to analyse the dynamics of burnout and the effects of sleep. In: Yang, X.-S., Sherratt, S., Dey, N., Joshi, A. (eds.) Fourth International Congress on Information and Communication Technology. AISC, vol. 1027, pp. 219-232. Springer, Singapore (2020). https://doi.org/10.1007/978-98132-9343-4_18

6. Borsboom, D., Cramer, A.O.: Network analysis: an integrative approach to the structure of psychopathology. Ann. Rev. Clin. Psychol. 9, 91-121 (2013)

7. Treur, J.: Network-Oriented Modeling: Addressing Complexity of Cognitive, Affective and Social Interactions. UCS. Springer, Cham (2016). https://doi.org/10.1007/978-3-319-45213-5

8. Treur, J.: Network-Oriented Modeling for Adaptive Networks: Designing Higher-Order Adaptive Biological, Mental and Social Network Models. SSDC, vol. 251. Springer, Cham (2020). https://doi.org/10.1007/978-3-030-31445-3

9. Maslach, C., Jackson, S.E.: The measurement of experienced burnout. J. Organ. Behav. 2(2), 99-113 (1981)

10. Huang, L., Zhou, D., Yao, Y., Lan, Y.: Relationship of personality with job burnout and psychological stress risk in clinicians. Chin. J. Ind. Hyg. Occup. Dis. 33(2), 84-87 (2015)

11. Emilia, I., Gómez-Urquiza, J.L., Cañadas, G.R., Albendín-García, L., Ortega-Campos, E., Cañadas-De la Fuente, G.A.: Burnout and its relationship with personality factors in oncology nurses. Eur. J. Oncol. Nurs. 30, 91-96 (2017)

12. Sutin, A.R., Stephan, Y., Luchetti, M., Artese, A., Oshio, A., Terracciano, A.: The five-factor model of personality and physical inactivity: a meta-analysis of 16 samples. J. Res. Pers. 63, 22-28 (2016)

13. Söderström, M., Jeding, K., Ekstedt, M., Perski, A., Åkerstedt, T.: Insufficient sleep predicts clinical burnout. J. Occup. Health Psychol. 17(2), 175-183 (2012)

14. Treur, J.: Modeling higher-order adaptivity of a network by multilevel network reification. Netw. Sci. J. (2020, in press)

15. Levin, R., Nielsen, T.: Nightmares, bad dreams, and emotion dysregulation: a review and new neurocognitive model of dreaming. Curr. Dir. Psychol. Sci. 18(2), 84-88 (2009)

16. Walker, M.P., van der Helm, E.: Overnight therapy? The role of sleep in emotional brain processing. Psychol. Bull. 135(5), 731-748 (2009)

17. Pace-Schott, E.F., Germain, A., Milad, M.R.: Effects of sleep on memory for conditioned fear and fear extinction. Psychol. Bull. 141(4), 835-857 (2015)

18. Kempter, R., Gerstner, W., Van Hemmen, J.L.: Hebbian learning and spiking neurons. Phys. Rev. E 59(4), 4498 (1999) 